\title{
RESEARCHES REGARDING ESTRUS INDUCTION AND SYNCHRONIZATION IN SOWS AFTER WEANING
}

\author{
Professor Liviu BOGDAN*, PhD \\ Professor loan GROZA*, PhD \\ Assistant Mihai CENARIU*, PhD \\ Lecturer Simona CIUPE*, PhD \\ Emoke PALL*, PhD Student \\ Anamaria PETREAN*, PhD Student \\ Sorana MATEI*, PhD Student \\ Sidonia BOGDAN**, student
}

\begin{abstract}
The purpose of this paper was to improve the reproductive performances of sows after weaning in a private swine farm. The main objective was to implement modern reproductive biotechnologies (estrus synchronization, artificial insemination and early pregnancy diagnosis) in order to increase the economic efficiency of the reproductive sector of this farm. The biologic material used for the research was represented by 300 sows whose estrus was synchronized using three hormonal procedures (Regu-Mate administered collectively, Regu-Mate administered individually and PG600) as well as naturally, using stimulating boars. The results showed that the best methods of estrus induction and synchronization in sows use either Regu-Mate administered individually in fodder or PG600.
\end{abstract}

Key words: sows, estrus, synchronization, artificial insemination, pregnancy, weaning

\section{Introduction}

Swine breeding has developed as a necessity meant to ensure meat for consumption, therefore the main objective of this industry is to maximize production. Swine have the ability to produce a large number of offspring during a short period of time [1,4]. Thus, pigs may represent one of the most profitable species among the farm animals. Profitability of this sector is largely dependent on the reproductive performance $[2,3]$. Therefore, the main purpose is to wean as many good quality piglets from a sow as possible during a year, with as little expenses as possible [5,6]. The implementation of

\footnotetext{
* University of Agricultural Sciences and Veterinary Medicine, Faculty of Veterinary Medicine, Department of Veterinary Reproduction, Obstetrics and Gynecology, 3-5 Manastur Street, 400372 Cluj-Napoca, Romania, tel. +40 264596384 ext. 163, e-mail: medivetbogdan@yahoo.com

** University of Agricultural Sciences and Veterinary Medicine, Faculty of Veterinary Medicine
}

Cluj Veterinary Journal, 15(1)/2009, pp. 24-28 
new biotechnological methods for estrus induction and synchronization in reproduction programs allows the improvement of technological and economical parameters $[7,8]$.

The purpose of this paper was to improve the reproductive performances of sows after weaning in a private swine farm. The main objective was to implement modern reproductive biotechnologies (estrus synchronization, artificial insemination and early pregnancy diagnosis) in order to increase the economic efficiency of the reproductive sector of this farm.

\section{Material and methods}

The research has been carried out during November 2008 - May 2009 in a private swine farm from Mures County, Romania. The farm had a total of 8900 pigs out of which 800 were mother sows, 165 awaiting sows and 13 boars, the rest being used for meat production. The boars belonged to the following breeds: White Duroc, Maxter, Pietrain and Great White, while the sows were mixed breeds between PIC and one of the previously mentioned boars.

The average productive life of the sows was of 5-6 parturitions, with an average of 12 piglets/ parturition and 11.5-11.8 weaned piglets/sow.

The biologic material used for the research was represented by 300 sows, 1-4 years of age, mixed breed between PIC and Great White, Duroc and Pietrain boars.

Estrus induction and synchronization was performed using three hormonal procedures (ReguMate administered collectively, Regu-Mate administered individually and PG600 - figure 1) as well as naturally, using stimulating boars.

The sows were divided into four batches as follows:

Batch 1 made up of 75 sows whose estrus was induced using the collective administration of ReguMate in the fodder;

Batch 2 made up of 75 sows whose estrus was induced using the individual administration of Regu-Mate in the fodder;

Batch 3 made up of 75 sows whose estrus was induced using PG600;

Batch 4 made up of 75 control sows.

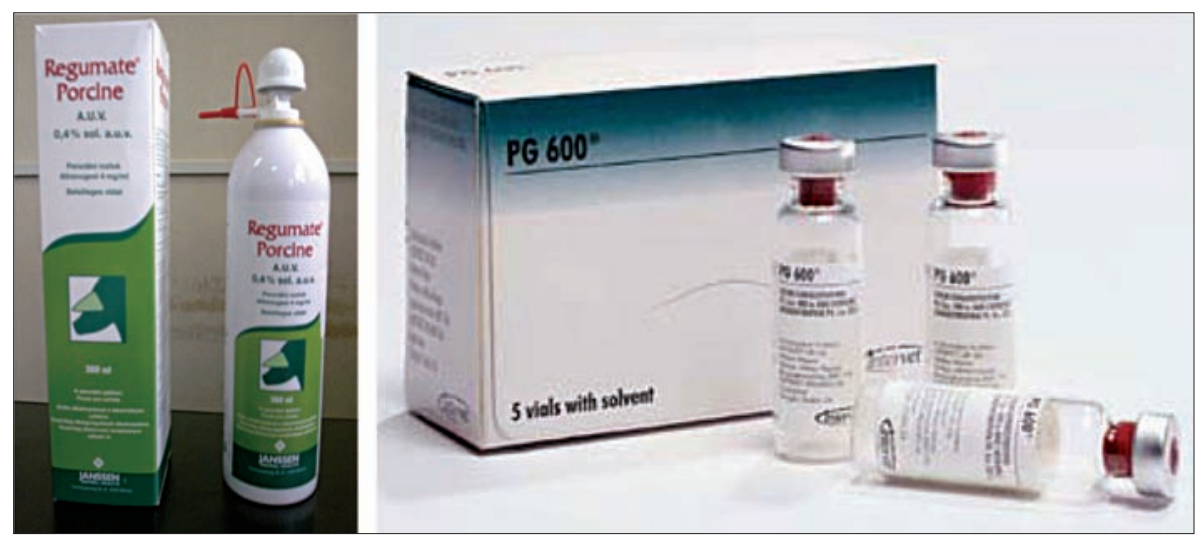

Fig. 1. The hormonal products used

Semen collection was performed using the manual method, which is efficient and does not imply supplementary costs. The dilution of fresh semen was performed using the TriXcel dilution media that maintains the viability of spermatozoa for 7 days (figure 2). 


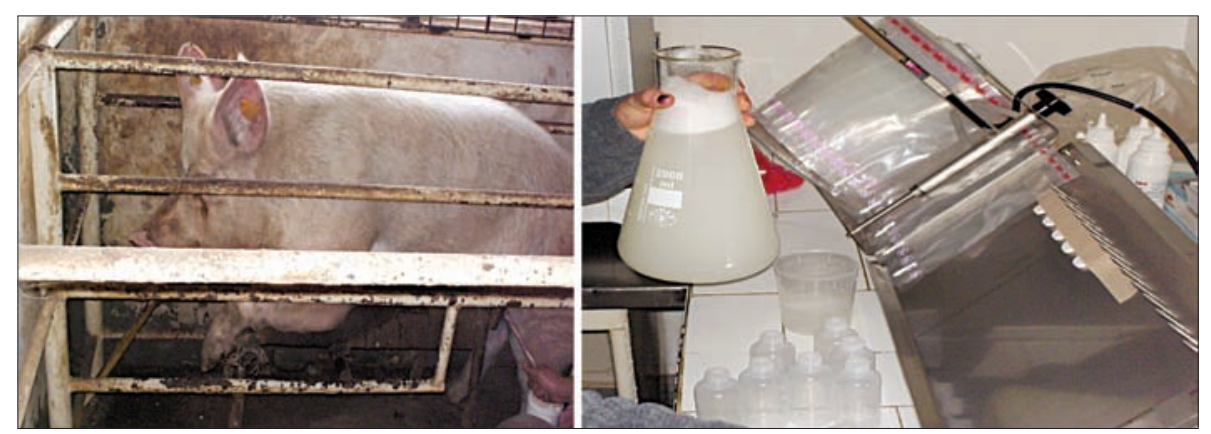

Fig. 2. Semen collection and dillution

The optimum moment for insemination was chosen 24 hours after the observation of the immobility syndrome. The sows were artificially inseminated (A.I.) twice (in the morning and in the evening) using $50 \mathrm{ml}$ diluted semen/ dose, with a concentration of 3 billions spermatozoa/dose (fig. 3). The pregnancy diagnosis was performed 30 days after artificial insemination in all sows, using a Doppler device (fig. 4).

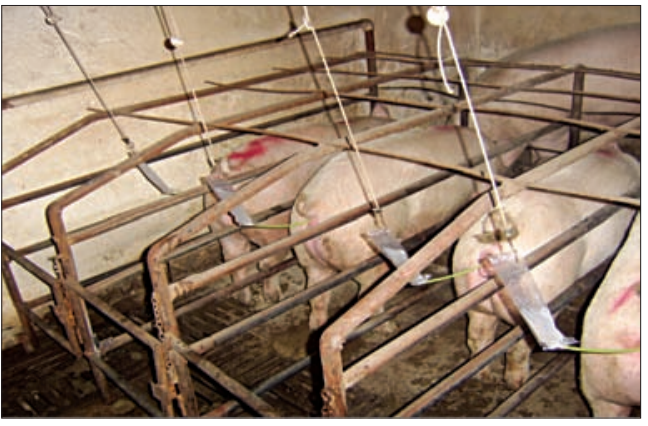

Fig. 3. A.l. of sows

\section{Results and Discussions}

Following estrus synchronization in batch 1, 67 sows (90\%) showed heat symptoms after 5-8 days. The remaining 8 sows (10\%) did not show estrus signs during this period.

From the 75 sows, 52 (69\%) were diagnosed pregnant after the first insemination, 15 (20\%) after the second insemination while 8 (11\%) did not show estrus signs and therefore were eliminated from the batch. The results obtained for batch 1 are shown in table 1:

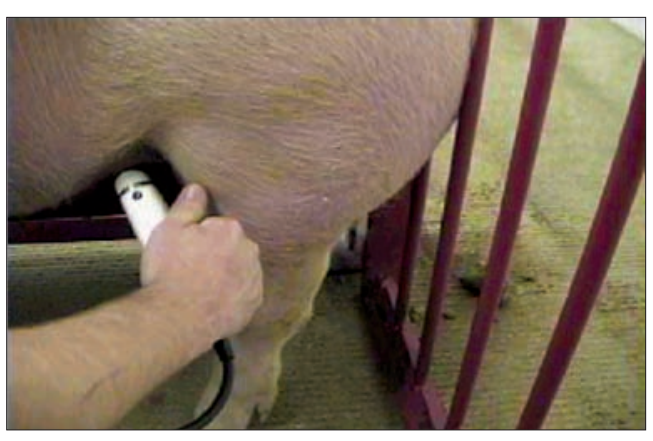

Fig. 4. Pregnancy diagnosis

Table 1. Results obtained for batch 1

\begin{tabular}{|c|l|c|c|}
\hline \multirow{2}{*}{ No. } & & \multicolumn{2}{|c|}{ REGU-MATE collectively in fodder } \\
\cline { 3 - 4 } & & Number of sows & Percent \\
\hline 1. & Number of sows/batch & 75 & $100 \%$ \\
\hline 2. & Sows in heat & 67 & $90 \%$ \\
\hline 3. & Sows that did not show heat signs & 8 & $11 \%$ \\
\hline 4. & Pregnant sows after first insemination & 52 & $69 \%$ \\
\hline 5. & Pregnant sows after the second insemination & 15 & $20 \%$ \\
\hline
\end{tabular}

Following estrus synchronization in batch 2, 73 sows (97\%) showed heat symptoms after 2-3 days. The remaining 3 sows (3\%) did not show estrus signs during this period.

From the 75 sows, 71 (94\%) were diagnosed pregnant after the first insemination, 2 (3\%) after the second insemination while $2(3 \%)$ did not show estrus signs and therefore were eliminated from the batch. The results obtained for batch 2 are shown in table 2 : 
Table 2. Results obtained for batch 2

\begin{tabular}{|c|l|c|c|}
\hline \multirow{2}{*}{ No. } & \multirow{2}{*}{} & REGU-MATE individually in fodder \\
\cline { 3 - 4 } & & Number of sows & Percent \\
\hline 1. & Number of sows/batch & 75 & $100 \%$ \\
\hline 2. & Sows in heat & 73 & $97 \%$ \\
\hline 3. & Sows that did not show heat signs & 2 & $3 \%$ \\
\hline 4. & Pregnant sows after first insemination & 71 & $94 \%$ \\
\hline 5. & Pregnant sows after the second insemination & 2 & $3 \%$ \\
\hline
\end{tabular}

Following estrus synchronization in batch 3, 74 sows (98\%) showed heat symptoms after 2-3 days. The remaining sow (2\%) did not show estrus signs during this period. From the 75 sows, 71 (81\%) were diagnosed pregnant after the first insemination, 13 (17\%) after the second insemination while 1 sow (2\%) did not show estrus signs and therefore was eliminated from the batch. The results obtained for batch 3 are shown in table 3 :

Table 3. Results obtained for batch 3

\begin{tabular}{|c|l|c|c|}
\hline \multirow{2}{*}{ No. } & \multirow{2}{*}{} & \multicolumn{2}{|c|}{ PG 600 i.m. } \\
\cline { 3 - 4 } & & Number of sows & Percent \\
\hline 1. & Number of sows/batch & 75 & $100 \%$ \\
\hline 2. & Sows in heat & 74 & $98 \%$ \\
\hline 3. & Sows that did not show heat signs & 1 & $2 \%$ \\
\hline 4. & Pregnant sows after first insemination & 61 & $81 \%$ \\
\hline 5. & Pregnant sows after the second insemination & 13 & $17 \%$ \\
\hline
\end{tabular}

In batch 4 (control), 67 (90\%) sows showed estrus signs 5-10 days after weaning. The remaining 8 sows (10\%) did not show estrus signs during this period.

From the 75 sows, 52 (69\%) were diagnosed pregnant after the first insemination, 15 (20\%) after the second insemination while 8 (11\%) did not show estrus signs and therefore were eliminated from the batch. The results obtained for batch 4 are shown in table 4 :

Table 4. Results obtained for batch 4

\begin{tabular}{|c|l|c|c|}
\hline \multirow{2}{*}{ No. } & \multirow{2}{*}{ CONTROL } \\
\cline { 3 - 4 } & & Number of sows & Percent \\
\hline 1. & Number of sows/batch & 75 & $100 \%$ \\
\hline 2. & Sows in heat & 67 & $90 \%$ \\
\hline 3. & Sows that did not show heat signs & 8 & $11 \%$ \\
\hline 4. & Pregnant sows after first insemination & 52 & $69 \%$ \\
\hline 5. & Pregnant sows after the second insemination & 15 & $20 \%$ \\
\hline
\end{tabular}

After delivery and weaning of the resulted piglets belonging to the four batches, the following results have been obtained (table 5):

Table 5. Results obtained after delivery and weaning

\begin{tabular}{|c|c|c|c|c|c|}
\hline No. & & Delivered piglets & Average/sow & Weaned piglets & Average/sow \\
\hline 1. & Batch 1 & 624 & 12 & 468 & 9 \\
\hline 2. & Batch 2 & 994 & 14 & 710 & 10 \\
\hline 3. & Batch 3 & 793 & 13 & 610 & 10 \\
\hline 4. & Batch 4 & 624 & 12 & 468 & 9 \\
\hline
\end{tabular}




\section{Conclusions}

After performing the research, the following conclusions were drawn:

1. The best results for estrus induction and synchronization were obtained in batch 2 and 3 where individual administration of Regu-Mate and PG600 were used.

2. The number of piglets delivered was also bigger in these two batches, as well as the number of weaned piglets.

3. Synchronization of estrus cycle leads to a short service-period and therefore to a larger number of deliveries/productive life of a sow.

4. Estrus synchronization also allows the decrease of boar number used for semen collection and therefore the number of artificial inseminations.

5. Delivery monitoring avoids the inherent accidents during parturition (dystokia, large fetuses, female exhaustion).

\section{References}

1. Bogdan L. M.: Biotehnici în reproducţia animalelor domestice, Ed. Academic Press, Cluj-Napoca, 2000;

2. Bogdan L.M.: Reproducţie, obstetrică, terapie şi însămânţări artificiale la animale, Ed. AcademicPres Cluj-Napoca, 2001;

3. Cardenas H., HeRrick J.R., PoPe W.F. : Increased ovulation rate in gilts treated with dihydrotestosterone, Reproduction, vol. 123, 2002;

4. Groza I., Muntean M.: Elemente de fiziologia reproducţiei la animale, Ed. Academic Press, Cluj-Napoca, 2002;

5. Groza I., Morar I., Andrologie Veterinară, Ed. Gryphon, Braşov, 2004;

6. Michel R. Muirhead, Thomas JL. Alexander: Managing Pig Health and the Treatment of Disease, The Word Renound Book, 2002;

7. Wise T., Klindt J., Howard H.J., Conley A.J., Ford J.J.: Endocrine relationships of Meishan and White composite females after weaning and during the luteal phase of the estrous cycle, vol. 79, 2001;

8. Yen H.W., Ford J.J., Zimmerman D.R., Johnson R.K.: Follicular development and maturation in gilts selected for an index of high ovulation rate and high prenatal survival, Departament of Animal Science, University of Nebraska, U.S. Meat Animal Research Center. 